\title{
Numerical Simulation Study on the Failure Mode of Soil-structure Contact Interface
}

\author{
Peng Du ${ }^{1,2, a}$, Xiaoling Liu ${ }^{1, b}$, Bo Yang ${ }^{1, c}$ \\ ${ }^{1}$ Institute of Engineering and Technology, Haikou College of Economics, Haikou Hainan, China \\ ${ }^{2}$ Hainan Zhongke Construction Test Center, Haikou Hainan, China \\ aPengdu_ctgu@163.com, 'liuxiaoling1042@163.com
}

\begin{abstract}
Keywords: soil-structure interaction, contact interface, numerical simulation, failure mode
Abstract: Direct shear test is recommended as a rational test approach for understanding of the behavior of soil-structure interface. Based on the ABAQUS software, a 3DFEM model is established and the direct shear test process of soil-concrete contact is simulated. The analysis about the soil shear stress-deformation under different normal stress has been done. The results show that the ABAQUS finite software can better simulate the soil-structure interaction. The contact failure mode of node and interface is revealed by contact node shear stress-displacement curve and contact state nephogram on the development process of shear failure.
\end{abstract}

\section{Introduction}

Soil and structure interface problem is an important component of interaction between soil and structure. In the process of stress and deformation of soil and structure system, the complex interaction between soil and structure is happened, which make the mechanical properties of soil near the contact area and other area obviously different, and mechanical response of the contact surface is an important impact on the forced deformation of the structure. In the process of the interaction between soil and structure, in addition to the correct understanding of the interface mechanical properties, the contact interface failure mode between soil and structure also need to be researched, the part is relatively few research results. However, at present, there are few researches on it. Through the finite element software ABAQUS, the 3-dimension mode of direct shear test between soil and structure is established, and this paper carried out the study of the contact failure mode of node and interface.

\section{Finite element numerical simulation of contact problem}

\section{Material parameters}

Soil is a cylinder with the diameter of $50 \mathrm{~cm}$ and $40 \mathrm{~cm}$ high. The concrete structure is $40 \mathrm{~cm}$ high rectangle with the length and width $70 \mathrm{~cm}$. In the shear process, the soil and concrete contact area always remains the same, which can avoid the influence on contact stress deformation. Material mechanics parameters are shown in table 1.

Tab.1 Material mechanics parameters

\begin{tabular}{cccccc}
\hline & $\begin{array}{c}\text { Modulus of elasticity } \\
(\mathrm{Pa})\end{array}$ & Poisson's ratio & $\begin{array}{c}\text { cohesion } \\
(\mathrm{Pa})\end{array}$ & $\begin{array}{c}\text { dilatancy angle } \\
\left({ }^{\circ}\right)\end{array}$ & $\begin{array}{c}\text { Friction Angle } \\
\left({ }^{\circ}\right)\end{array}$ \\
\hline soil & $2.5 \times 10^{8}$ & 0.45 & $1.9 \times 10^{4}$ & 30 & 32 \\
structure & $2.5 \times 10^{10}$ & 0.2 & $/$ & $/$ & $/$ \\
\hline
\end{tabular}




\section{Numerical model}

On the boundary and loading conditions: upper box sets X, Y direction of boundary constraints, applying respectively normal stress with size of $100,200,300,500,1000 \mathrm{kPa}$ s on the top surface soil; the bottom of the lower box sets $\mathrm{Y}$ and $\mathrm{Z}$ direction constraints. Applying horizontal displacement load of $0.01 \mathrm{~m}$ on the side.

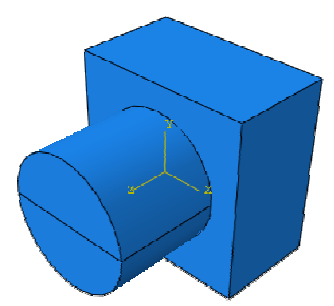

Fig.1 Soil and concrete contact model

\section{The calculation results and analysis}

Interface shear stress distribution
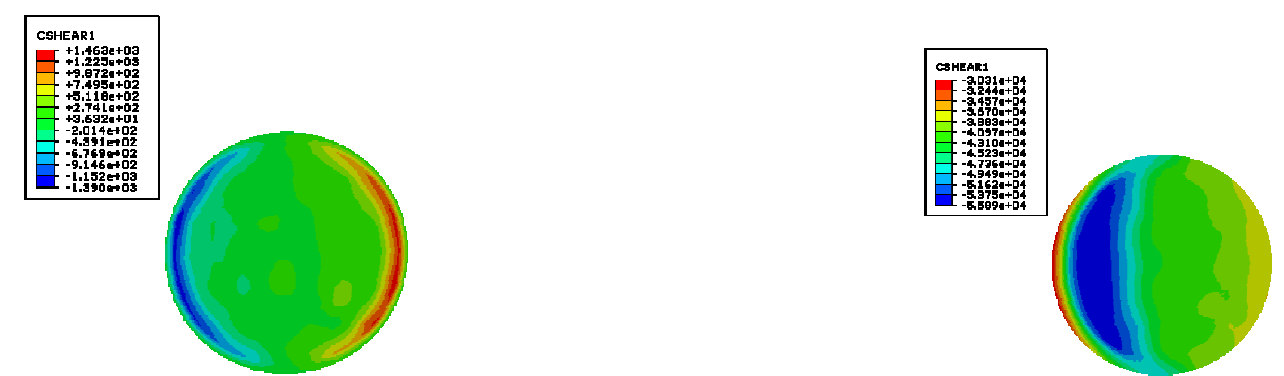

Fig. (a) Shear stress nephogram at the beginning of shear Fig. (b) Shear stress nephogram at the end of shear

\section{Fig. 2 Interface shear stress distribution}

Figure 2 shows the interface shear stress distribution nephogram at the beginning and end of shear, when the normal stress is 100kpa. Figure (a) and (b) comparison shows: the distribution of Interface shear stress is uneven, at the beginning of Shear the left and right edges appear two shear stress area, and at the end of the shear contact area in the left side there was a big shear stress area.

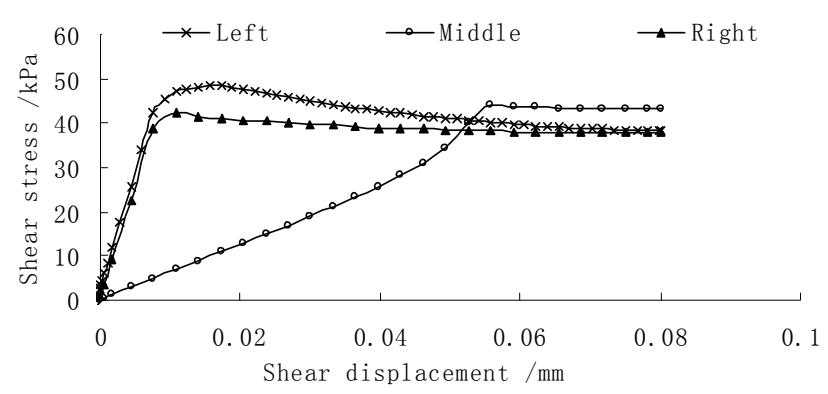

Figure. 3 The shear stress-displacement curve in different parts of the contact interface

Figure 3 shows that the shear stress-displacement curve In different parts of the contact interface, the interface nodes on the central, left and right side are selected as the research object. The figure shows that the distribution of Interface shear stress is uneven, and there are difference in shear stress change rule of the left, middle and right nodes, but when the shear displacement increases to certain value, shear stress distribution tends to be stable. The shear stress development trend of the edge nodes in the left and right side are consistent, With the increase of the shear displacement, shear stress increases rapidly and finally stabilize, and the development of central node is relatively slower. Therefore, compared with the central node, left and right edge damage first. 


\section{Contact node failure mode}

By the time history analysis of ABAQUS, the shear stress of the central node and shear displacement relationship curve, also the shear displacement of the central node and shear displacement relationship curve, can be obtained, so The curve of the contact node shear stress and displacement is obtained, The following figure 4, 5 .

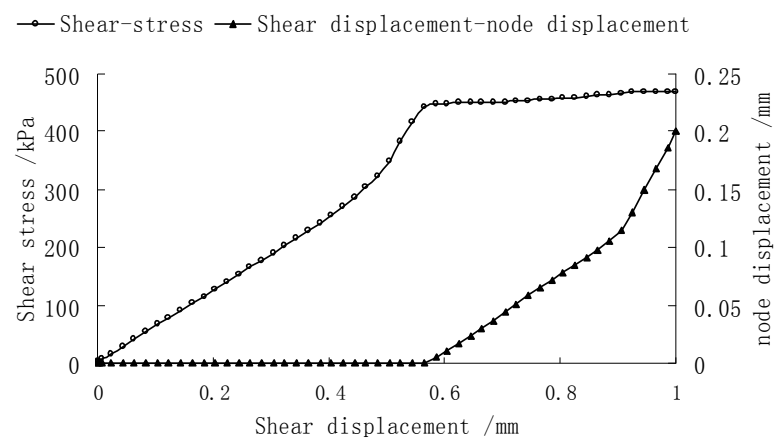

Fig. 4 The curve of shear stress and node displacement-shear displacement

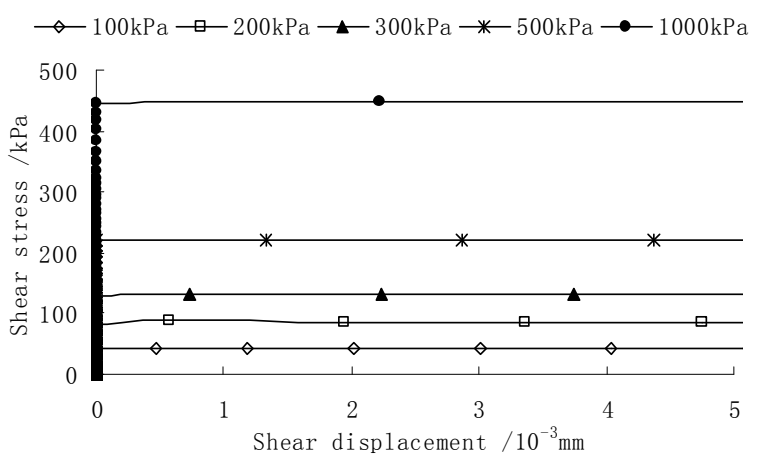

Fig. 5 The curve of the contact node shear stress and displacement

Figure 4 shows the relationship curve of the shear stress, node displacement-shear displacement, In $0 \sim 0.55 \mathrm{~mm}$, shear stress increases gradually and tends to peak as the shear displacement increases, but interface node don't move basically; when the shear displacement is about 0.55 $\mathrm{mm}$, node displacement began to change, while the shear stress has reached a peak. From figure 4, the curve of shear stress and node displacement can be obtained as shown in figure 5, the relationship between shear stress and node displacement is rigid-plastic model, and this results is consistent with Zong-ze Yin, etc[1].

Contact interface failure mode
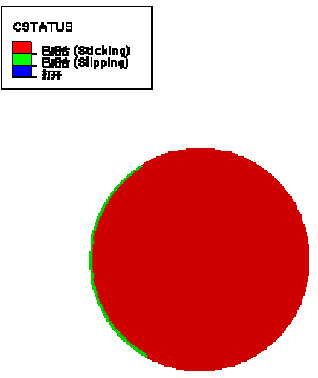
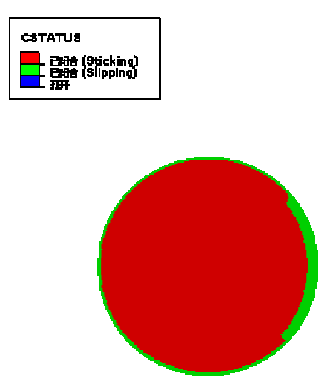
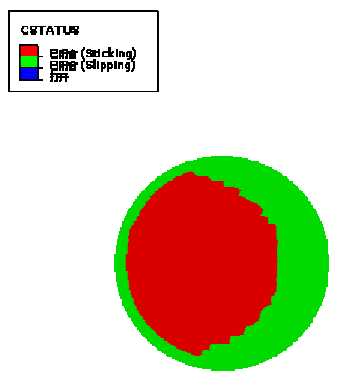
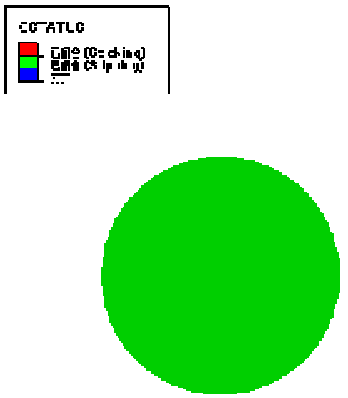

Figure. (a) $\mathrm{w}_{\mathrm{s}}=0.084 \mathrm{~mm}$ Figure. (b) $\mathrm{w}_{\mathrm{s}}=0.093 \mathrm{~mm} \quad$ Figure. (c) $\mathrm{w}_{\mathrm{s}}=0.324 \mathrm{~mm}$ Figure. (d) $\mathrm{w}_{\mathrm{s}}=0.916 \mathrm{~mm}$ Fig.6 Contact state nephogram on the development process of shear failure 
Figure 6 shows the contact state nephogram on the development process of shear failure, along with the increase of the shear displacement, when the normal stress is $1000 \mathrm{kpa}$. When the shear displacement $\left(\mathrm{w}_{\mathrm{s}}\right)$ is $0.084 \mathrm{~mm}$, the figure(a) shown contact element left edge first appeared bond-slip destruction; in figure(b), the development of interface shear failure is from the left edge to the right edge gradually, when the shear displacement is $0.093 \mathrm{~mm}$, contact edge all linked together and damage, With the increase of the horizontal shear displacement, the interface shear failure is gradually towards to the middle area, as shown in figure (c); when the shear displacement is 0.916 $\mathrm{mm}$, the entire interface realize completely sliding failure. according to the stress nephogram, the shear failure of contact interface is revealed to be a gradual process from the edge to the inner.

\section{Contact interface shear stress-displacement curve}

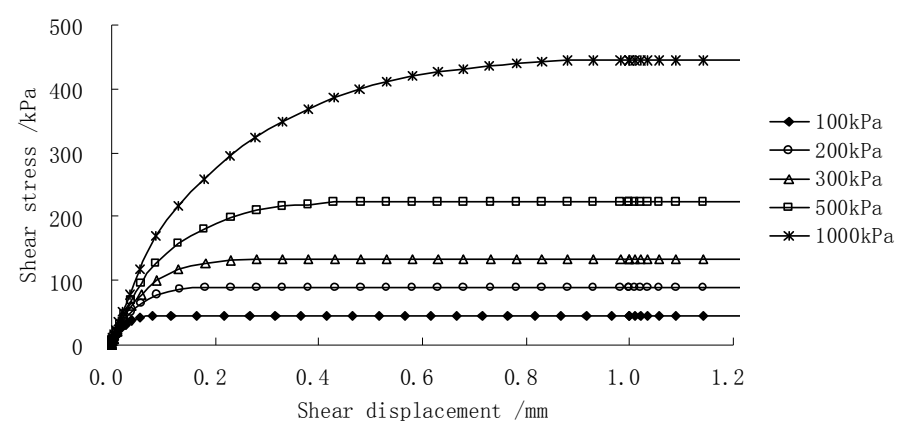

\section{Fig.7 Contact interface shear stress-displacement curves}

From figure 7, the interface shear stress-displacement relationship curve is approximation as hyperbola model [2]; with the increase of the relative shear displacement, the interface shear stress value also increased gradually and stable; with the increase of initial normal stresses, peak shear stress also increases.

\section{Conclusion}

ABAQUS finite element software can well simulate the contact direct shear test between soil and structure, which provides another feasible method to understand the test process and experimental principle. By analyzing the results of numerical calculation, the finite element software ABAQUS can better simulate the soil and the structure of (concrete) contact problem, by the curve of shear stress and node displacement, the relationship between shear stress and node displacement is rigid-plastic model; according to the stress nephogram, the shear failure of contact interface is revealed to be a gradual process from the edge to the inner.

\section{Acknowledgements}

This work was financially supported by the Hainan Natural Science Foundation (514219), 2014 College Project of Haikou College of Economics (hjky14-12).

\section{References}

[1] Zong-ze Yin, Zhu Hong, Kuo-hua Xu. Interface deformation of the soil and structural material and Mathematical simulation [J]. Journal of geotechnical engineering, 1994, (03).

[2] CLOUGH G W, Duncan J M. Finite Element Analyses of Retaining Wall Behavior[J]. Journal of Soil Mechanic and Foundation Division, ASCE, 1971, 97(SM12):1657-1674. 